\title{
Biomarkers of acute myocardial infarction in the elderly: troponin and beyond
}

This article was published in the following Dove Press journal:

Clinical Interventions in Aging

II July 2014

Number of times this article has been viewed

\author{
Martin G Rains' \\ Charles A Laney' \\ Alison L Bailey' \\ Charles L Campbell ${ }^{1,2}$ \\ 'Gill Heart Institute, Division of \\ Cardiovascular Medicine, University \\ of Kentucky, Lexington, KY, USA; \\ ${ }^{2}$ Lexington Veterans Administration \\ Hospital, Lexington, KY, USA
}

Correspondence: Charles L Campbell University of Kentucky, 900 South Limestone Street, 326 Charles $T$ Wethington Building, Lexington, KY 40536-0200, USA

Email clcampbell@uky.edu

\begin{abstract}
In the broadest context, biological markers, or biomarkers, are molecules that characterize a biological system or process. In the setting of cardiovascular disease, a number of biomarkers have become an integral part of diagnostic and risk stratification strategies. In this review, we will discuss classic and emerging biomarkers of cardiovascular disease and the role of these biomarkers in the diagnosis and prognosis of elderly patients presenting with acute myocardial infarction.
\end{abstract}

Keywords: cardiovascular disease, biological markers, diagnosis, prognosis

\section{Acute coronary syndromes in the elderly}

Ischemic heart disease (coronary artery disease, angina pectoris, and myocardial infarction) is commonly encountered in the current medical era. Data from the 2007-2010 National Health and Nutrition Examination Survey suggests $6.4 \%$ of all Americans $>20$ years old (15.4 million adults) have some form of ischemic heart disease. Not surprisingly, the prevalence of symptomatic ischemic heart disease increases with age. United States census data for 2012 revealed a total population of 313 million persons, with 61 million ( $20 \%$ ) being categorized as elderly ( $\geq 60$ years). ${ }^{1}$ Of these individuals, about $21 \%$ of men and $11 \%$ of women aged $60-79$ years have ischemic heart disease; the numbers jump to $35 \%$ of men and $19 \%$ of women aged $\geq 80$ years. In the United States, 180,000 men and 210,000 women over the age of 75 suffer an acute myocardial infarction (AMI) or die from coronary heart disease every year. The estimated direct and indirect cost of ischemic heart disease was $\$ 195.2$ billion in 2009. This number is projected to increase $\sim 100 \%$ from 2013 to $2030{ }^{2}$

\section{Biomarkers of myocardial necrosis}

In the broadest context, biological markers, or biomarkers, are molecules that characterize a biological system or process. They are measured in a variety of situations and may indicate normal physiology, identify pathologic states, or be used to monitor a therapeutic response. Ideally, biomarkers affect therapy by identifying patients likely to benefit from a therapeutic intervention or in whom a more aggressive diagnostic strategy should be undertaken. In the setting of cardiovascular disease (CVD), biomarkers, particularly cardiac troponins (cTn) have become an integral part of diagnostic strategies. Other biomarkers alone or in combination have been shown to identify patients at high risk for subsequent adverse outcomes, but have not been shown to predict a response to a particular therapeutic strategy. 
Traditionally, creatinine kinase (CK), lactate dehydrogenase, and aspartate aminotransferase were used to evaluate for myocardial damage among patients presenting with chest pain. While sensitive for detecting cellular death, these biomarkers lacked specificity for myocardial injury. Later, the myocardial band (MB) isoform of CK (CK-MB) and serum myoglobin levels were utilized to improve specificity for cardiac damage and reduce the time to diagnosis (Figure 1). In the last two decades, the measurement of serum troponin level has become the predominant biomarker for the detection of myocardial necrosis. In this review, we will discuss the evolution of troponin as the quintessential biomarker for the diagnosis of AMI.
We will also discuss newer biomarkers being evaluated as part of a multimarker approach for the diagnosis of AMI.

\section{Serum troponin and the diagnosis of AMI}

Cardiac troponin I (cTnT) and troponin I (cTnI) are both structural proteins found in the contractile apparatus of cardiac myocytes (Figure 1). Both of these molecules are coded by single genes that are not expressed outside of the cardiac myocyte. In the myocyte, troponin is found in two "pools"; the majority ( 95\%) is bound to actin filaments in the sarcomere and is released into the systemic circulation
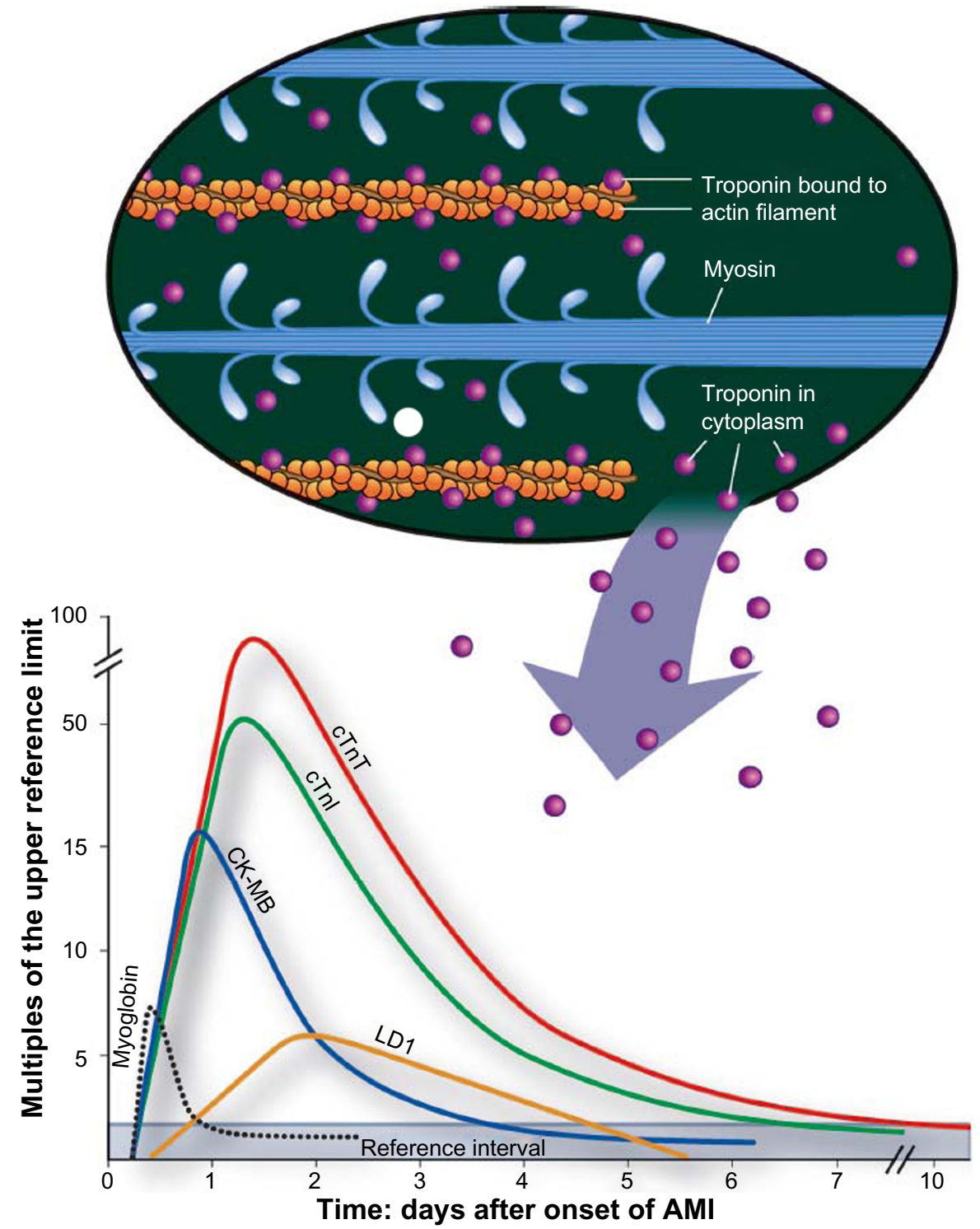

Figure I The cardiac sarcomere showing the sites at which troponin $\mathrm{T}$ and I are active.

Notes: The temporal release pattern of the classic biomarkers of myocardial infarction including cTnT, cTnl, CK-MB, myoglobin, and LDI. Reprinted with permission from Lippincott Williams \& Wilkins/Wolters Kluwer Health: Anesthesiology. Archan S, Fleisher LA. From creatine kinase-MB to troponin: the adoption of a new standard. I I2(4): I005-1012.50 Copyright (C) 2010 Wolters Kluwer Health. Promotional and commercial use of the material in print, digital or mobile device format is prohibited without the permission from the publisher Lippincott Williams \& Wilkins. Please contact journalpermissions@lww.com for further information.

Abbreviations: AMI, acute myocardial infarction; CK-MB, creatine kinase myocardial band; cTnl, cardiac troponin I; cTnT, cardiac troponin T; LDI, lactate dehydrogenase I. 
when the myocyte dies. The "cytoplasmic" or "early appearing" pool of troponin is unbound and can be released into the circulation in the absence of cell death. ${ }^{3}$ Myocyte damage and cell death induces release of the "early pool" of cTn followed by release of the bound troponin. Levels usually peak 12-24 hours after injury, but may be present in circulation for weeks following a large AMI ${ }^{4}$

Early studies identified troponin as a more sensitive marker of AMI than CK-MB. ${ }^{5}$ Subsequently, "troponin positive", CK-MB "negative" patients were found to be at substantial short-term risk for recurrent myocardial infarction and mortality. ${ }^{6}$ Most importantly, troponin elevation alone was found to identify patients likely to benefit from intensive antiplatelet therapy or an early invasive management strategy. ${ }^{7,8}$ Eventually, elevated troponin levels were included in risk stratification schemes such as the TIMI-Risk Score and the GRACE-Risk Score. ${ }^{9,10}$

\section{The universal diagnosis of AMI}

The importance of cTn in the diagnosis and management of AMI was recently underscored by the development of a new "definition" of myocardial infarction. This universal definition of myocardial infarction is based on the detection of a rise and fall in troponin, with at least one value greater than the 99th percentile of the upper reference limit (URL) for the assay. This biomarker elevation must be accompanied with at least one of the following: symptoms suggestive of ischemia, new or presumed new ST changes of left bundle branch block, pathological Q-waves, imaging that indicates the loss of viable myocardium or a new regional wall motion abnormality, or identification of intracoronary thrombus at autopsy. ${ }^{11}$ With the advent and, now, routine use of biomarkers, the definition of an AMI has been transformed from a clinical diagnosis supported by electrocardiogram findings and biomarkers to a biomarker measurement supported by electrocardiogram and clinical findings. ${ }^{12}$

\section{Troponin assays}

There are several commercially available cTnI assays, but cTnT assays are produced by a single manufacturer. These assays are based on the affinity of an antibody for an epitope on the troponin molecule and vary significantly with respect to clinical performance, making it essential to understand the test characteristics of the specific product being used. To date, there is no agreement regarding the reference population used to characterize a particular assay; therefore, variability with respect to age, sex, and ethnicity is to be expected. Ideally, each hospital laboratory would perform reference testing independently to determine the precision of the assay and local "cutoff" points. This is generally not possible, and so a reliance on published values for reference limits and reliability exists.

In general, there are three characteristics of troponin assays that should be considered. The point at which a troponin concentration is deemed abnormal or "elevated" is based on a determination of the 99th percentile URL for a given assay. Using this definition, the risk that a healthy person, selected at random from the general population, has an abnormal troponin level is 0.01 (1\%). The coefficient of variability $(\mathrm{CV})$ is a measure of the imprecision of a laboratory test if the same sample were repeatedly analyzed. With respect to serum troponin assays, a CV of $<10 \%$ is considered ideal, and an assay with a CV of $>20 \%$ should not be utilized, in general. ${ }^{11}$ A CV between $10 \%$ and $20 \%$ may be of use, but may be associated with a few more misclassifications at low troponin concentrations. ${ }^{13}$ An ideal assay would then be characterized by a CV of $<10 \%$ at the 99 th percentile URL. Unfortunately, contemporary troponin assays are at the limits of their detection at low troponin levels and are often unable to deliver precise measurements at or below the 99th percentile URL ( $\mathrm{CV}>20 \%)$. In such situations, it has been recommended that a cutoff be set at the lowest point that can be measured with a $\mathrm{CV}$ of $<10 \% .{ }^{14}$ Regardless, a solitary elevation in cTnI or cTnT is considered insufficient for the diagnosis of AMI. In most cases, serial measurements drawn 3-6 hours apart are performed, and the diagnosis of AMI is established when a rise and fall in the level of cTnI or cTnT is detected. ${ }^{11}$

\section{Troponin elevations outside the setting of AMI}

It is important to note that the evidence substantiating the role of troponin in the diagnosis of AMI arises from studies in which the subjects had a relatively high pretest probability of having coronary artery disease and AMI. As with any diagnostic test, the reliability of the test decreases considerably when used in situations in which AMI is unlikely. At the time of development, it was hoped that elevations in cTn would be sensitive, but perhaps more importantly, exquisitely specific for myocardial injury. ${ }^{15}$ Unfortunately, experience with these assays has demonstrated numerous situations in which "elevated" cTn levels do not signal AMI. Specifically, it is known that patients with renal failure or chronic systolic or diastolic heart failure (HF) can have a persistently elevated cTn. ${ }^{16-18}$ Additionally, it has been noted that an elevated cTn can be associated with other life-threatening conditions such as 
aortic dissection, pulmonary embolism, and sepsis. ${ }^{19-21}$ Despite this lack of specificity, the test is frequently ordered. In one analysis, a serum troponin level was ordered in $48 \%$ of patients presenting to an emergency department, only $29 \%$ of whom were admitted to "rule out" a myocardial infarction. ${ }^{22}$ Thus, it has become common for a cardiologist to be asked to evaluate a patient simply because of "an elevated troponin". ${ }^{23,24}$

\section{Troponin elevations in the elderly}

The current generation of troponin assays is poorly studied among elderly patients. The studies that established troponin as the diagnostic standard for AMI enrolled relatively young patients with a high pretest probability of AMI. ${ }^{6}$ Subsequent studies have found troponin elevations in "apparently healthy" subjects, especially those that are elderly. For example, in the Prospective Investigation of the Vasculature in Uppsala Seniors (PIVAS) study, 1,005 persons 70 years of age were evaluated for the presence of elevated cTnI levels. Using an assay with a lower limit of detection of $0.006 \mu \mathrm{g} / \mathrm{L}$ and "abnormal" cutoff value of $0.01 \mu \mathrm{g} / \mathrm{L}$, the authors found that $21.8 \%$ of these patients had an elevated cTnI level. Predictors of elevated cTnI included the male sex, cardiac risk factors, and impaired left ventricular systolic function. ${ }^{25}$ In contrast, in the Dallas Heart Study (DHS), 3,557 patients aged 30-65 years underwent a test for serum troponin using a cTnT assay with a lower detection limit of $0.01 \mu \mathrm{g} / \mathrm{L}$. A detectable troponin level was found in only $1 \%$ of these younger subjects ( $0.7 \%$; confidence interval $0.3 \%-1.1 \%) .{ }^{26}$ Thus, the diagnostic characteristics of the traditional troponin assays among elderly subjects remains to be definitively determined.

\section{Multiple biomarkers for the diagnosis of AMI}

The increasing sensitivity of troponin makes it unlikely another marker of myocardial necrosis will add considerably to diagnostic or prognostic algorithms for AMI. However, there are still patients in whom troponin levels at presentation are undetectable and who proceed to be diagnosed with an AMI. Recently, diagnostic strategies using a combination of biomarkers have been evaluated in hope of identifying high risk patients with chest pain. The combination of troponin and a biomarker that does not arise from myocardial necrosis but by a different mechanism such as myocardial stretch, inflammation, or stress is appealing.

\section{Natriuretic peptides}

Brain natriuretic peptide (BNP) is a natriuretic hormone produced by myocytes and was initially identified in the brain.
A prohormone is released in response to increased wall tension or myocardial stretch. Cleavage of the prohormone in circulation releases BNP and the more stable N-terminal fragment (NT-proBNP). Plasma concentrations of both of these hormones are elevated in patients with left ventricular dysfunction (systolic or diastolic) and are frequently used to aid in the diagnosis of clinical $\mathrm{HF}^{27}$ The measurement of NT-proBNP and BNP levels have become commonplace in the setting of HF. It has become evident, however, that NT-proBNP and BNP levels are also elevated in a variety of other situations associated with myocardial dysfunction, such as pulmonary embolism, sepsis, and myocardial infarction. ${ }^{28-30}$

\section{BNP and NT-proBNP in the elderly}

Plasma concentrations of BNP and NT-proBNP increase with increasing age. In fact, age appears to be the most important independent variable in explaining plasma levels of BNP and NT-proBNP. ${ }^{31,32}$ The reason for this increase is not entirely clear. Initial investigations suggested cardiac structural alterations (increased left ventricular mass, increased left atrial volume) and reduced renal clearance of the natriuretic peptides with aging. However, when BNP was studied in a population of more than 700 normal subjects in sinus rhythm without cardiovascular disease, renal disease, pulmonary disease, or diabetes, on no cardiovascular medications, and with normal cardiac function, age was still an independent predictor of BNP levels. ${ }^{32}$

\section{C-reactive protein}

Inflammation plays a central role in the development of atherosclerosis. C-reative protein (CRP) is a marker of inflammation. Elevations in CRP, especially when measured using highly sensitive assays (hs-CRP) have been shown to predict the presence of coronary disease among apparently healthy subjects and to predict adverse events in the setting of AMI. ${ }^{33,34}$

\section{Multimarker strategies}

The potential of serum cTnI, BNP, and hs-CRP to predict outcomes in AMI was established by evaluating blood samples collected from a subset of patients enrolled in a large clinical trial. Samples were drawn in 450 patients within 72 hours of presentation with AMI and sent to a core lab for analysis. Multivariable analysis indicated each of these biomarkers was an independent predictor of subsequent adverse outcomes including death, recurrent myocardial infarction, and the development of HF. A scoring system 
was developed that reflected the number of biomarkers that were elevated. The risk of mortality, recurrent myocardial infarction, or HF at 30 days increased in proportion to the number of biomarkers that were elevated. This scoring system was then validated in a larger cohort of patients enrolled in another clinical trial. ${ }^{35}$

The prognostic utility of NT-proBNP, hs-CRP, and cTnT and several other candidate biomarkers has been studied in a group of patients presenting with chest pain. Both NTproBNP and cTnT, but not hs-CRP, emerged as independent predictors of adverse events in the year following presentation (Figure 2). An elevated NT-proBNP ( $\geq 1,371 \mathrm{ng} / \mathrm{L})$ was associated with an adjusted odds ratio of 2.7 for death or AMI at 1 year. When the concentration of both NT-proBNP and cTnT exceeded the cutoff values, the risk of death or AMI at 1 year was $11.9 \%$ compared with $1.4 \%$ among patients in whom neither biomarker was elevated. ${ }^{36}$

\section{Future perspectives - emerging biomarkers \\ The next generation of troponin assays}

Newer troponin assays promise to be significantly more sensitive. These newer assays are in use in Europe and await approval from the US Food and Drug Administration before
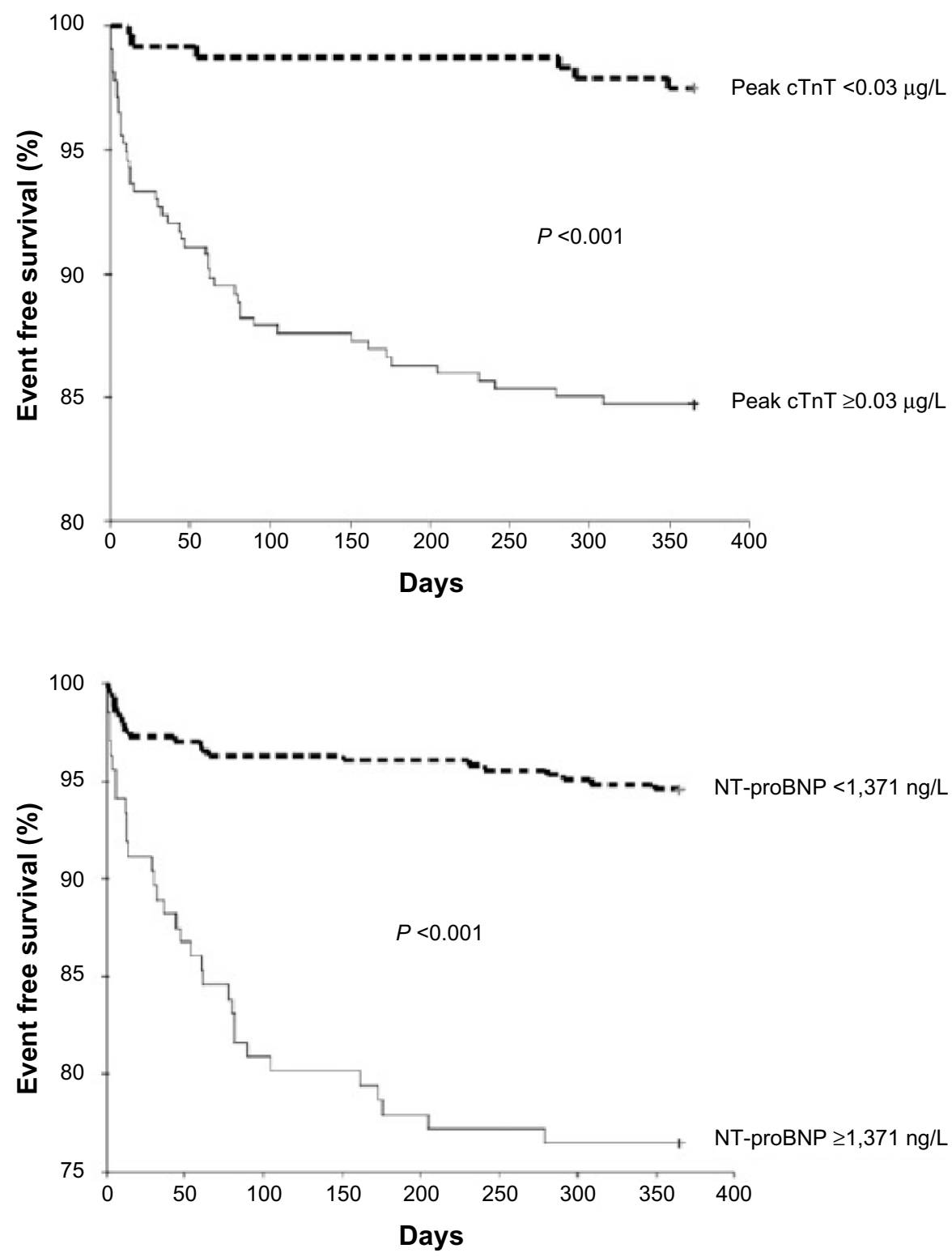

Figure 2 Kaplan-Meier curves demonstrating survival from death or myocardial infarction stratified by the level of cTnT ( $\geq 0.03 \mu \mathrm{g} / \mathrm{L})$ or NT-proBNP ( $<\mathrm{I}, 37 \mathrm{I}$ ng/L). Note: Reprinted from Am J Cardiol I03(I), McCann CJ, Glover BM, Menown IB, et al. Prognostic value of a multimarker approach for patients presenting to hospital with acute chest pain, pages $22-28 .{ }^{36}$ Copyright (C) 2009 with permission from Elsevier.

Abbreviations: cTnT, cardiac troponin T; NT-proBNP, N-terminal prohormone of brain natriuretic peptide. 
they enter the market in the United States. They have been given the name "high-sensitivity" troponin (hs-cTn) assays, as they detect troponin at concentrations tenfold lower than the currently utilized assays. That said, these assays are based on the same biochemistry as traditional troponin assays and are likely just the next, rather than the final, step along the path of improving sensitivity. The increased sensitivity will force providers to rethink how these assays are used (Table 1). For example, simply detecting troponin with these assays will not be suggestive of myocardial ischemia as there will be a measurable troponin level in many, if not most, persons admitted to emergency departments as well as a significant proportion of the general population. ${ }^{12}$

In the DHS, the ability of a traditional and highly sensitive cTnT assay to predict adverse events among a cohort of apparently healthy adults was compared. As noted above, $\sim 1 \%$ of apparently healthy patients had a detectable troponin level using a traditional troponin assay. The same samples were also analyzed using an hs-cTnT assay with a lower limit of detection of $3.0 \mathrm{ng} / \mathrm{L}$ and a 99 th percentile URL of $1.4 \mathrm{ng} / \mathrm{L}$. A detectable serum troponin was noted in $25 \%$ of these subjects. Elevated hs-cTnT was independently associated with all-cause and cardiovascular mortality in a concentration-dependent manner (Figure 3). ${ }^{37}$

In emergency departments, hs-cTn measurements promise to change practice patterns. A large study by Reichlin et al was recently performed in which the effectiveness of four sensitive cTn assays were evaluated among 718 patients presenting to the emergency department complaining of symptoms consistent with AMI. The hs-cTn assays all performed well when compared with a standard troponin assay, especially among patients presenting within a few hours of the onset of symptoms. Perhaps as importantly, the negative predictive value of these assays was quite high. In fact, when the 99th percentile URL was used as a cutoff, the negative predictive value was $97 \%-99 \% .^{38}$

Table I A comparison of contemporary and highly sensitive troponin assays

\begin{tabular}{|c|c|c|}
\hline Characteristic & Current assays & High sensitivity assays \\
\hline General & $\begin{array}{l}\text { There is a variety of available troponin assays } \\
\text { with unique test characteristics } \\
\text { - The test characteristics and cutoff values will } \\
\text { vary from assay to assay } \\
\text { - Elevated levels uncommon in "apparently } \\
\text { healthy adults" }\end{array}$ & $\begin{array}{l}\text { There is a variety of available troponin assays with } \\
\text { unique test characteristics } \\
\text { - Ten times more sensitive than conventional assays } \\
\text { - Elevated levels common in "apparently healthy" } \\
\text { adults } \\
\text { - "Cutoff" values will vary significantly across } \\
\text { reference populations and with age }\end{array}$ \\
\hline Diagnosis of AMI & $\begin{array}{l}\text { Elevated troponin levels in the appropriate clinical } \\
\text { setting are required for the diagnosis of AMI } \\
\text { - Serial measurements to detect a rise and fall } \\
\text { in troponin concentration will likely remain an } \\
\text { important part in the diagnosis of AMI }\end{array}$ & $\begin{array}{l}\text { Elevated troponin levels in the appropriate clinical } \\
\text { setting are required for the diagnosis of AMI } \\
\text { - Significantly improved sensitivity, which translates to } \\
\text { earlier detection } \\
\text { - Reduced specificity } \\
\text { - Serial measurements may still be required }\end{array}$ \\
\hline Exclusion of AMI & $\begin{array}{l}\text { The absence of a measurable troponin on a single } \\
\text { blood draw is insufficient to exclude AMI }\end{array}$ & $\begin{array}{l}\text { - The absence of a measurable troponin will likely } \\
\text { exclude AMI }\end{array}$ \\
\hline Non-cardiac disease & $\begin{array}{l}\text { Troponin levels may be elevated in a variety of } \\
\text { pathological states, some of which constitute } \\
\text { medical emergencies } \\
\text { - Aortic dissection } \\
\text { - Pulmonary embolism } \\
\text { - Shock } \\
\text { - Heart failure } \\
\text { - Chronic renal insufficiency }\end{array}$ & $\begin{array}{l}\text { Troponin levels may be elevated in a variety of } \\
\text { pathological states, some of which constitute medical } \\
\text { emergencies } \\
\text { - Aortic dissection } \\
\text { - Pulmonary embolism } \\
\text { - Shock } \\
\text { - Heart failure } \\
\text { - Chronic renal insufficiency }\end{array}$ \\
\hline Prognosis & $\begin{array}{l}\text { Elevated serum troponin levels appear to be } \\
\text { associated with a poor prognosis } \\
\text { - Especially among hospitalized patients }\end{array}$ & $\begin{array}{l}\text { Elevated serum troponin levels appear to be associated } \\
\text { with a poor prognosis } \\
\text { - May prove true among "apparently healthy } \\
\text { outpatients" }\end{array}$ \\
\hline $\begin{array}{l}\text { Pitfalls associated with the } \\
\text { elderly }\end{array}$ & $\begin{array}{l}\text { Limitations } \\
\text { - Few studies evaluate an elderly population }\end{array}$ & $\begin{array}{l}\text { Limitations } \\
\text { - Better studied in the elderly } \\
\text { - Troponin levels "measurable" in the majority of } \\
\text { elderly patients } \\
\text { - Age specific "cutoff" values may be needed }\end{array}$ \\
\hline
\end{tabular}

Note: Data from Mohammed and Januzzi, ${ }^{51}$ and Korley and Jaffe. ${ }^{52}$

Abbreviation: AMI, acute myocardial infarction. 


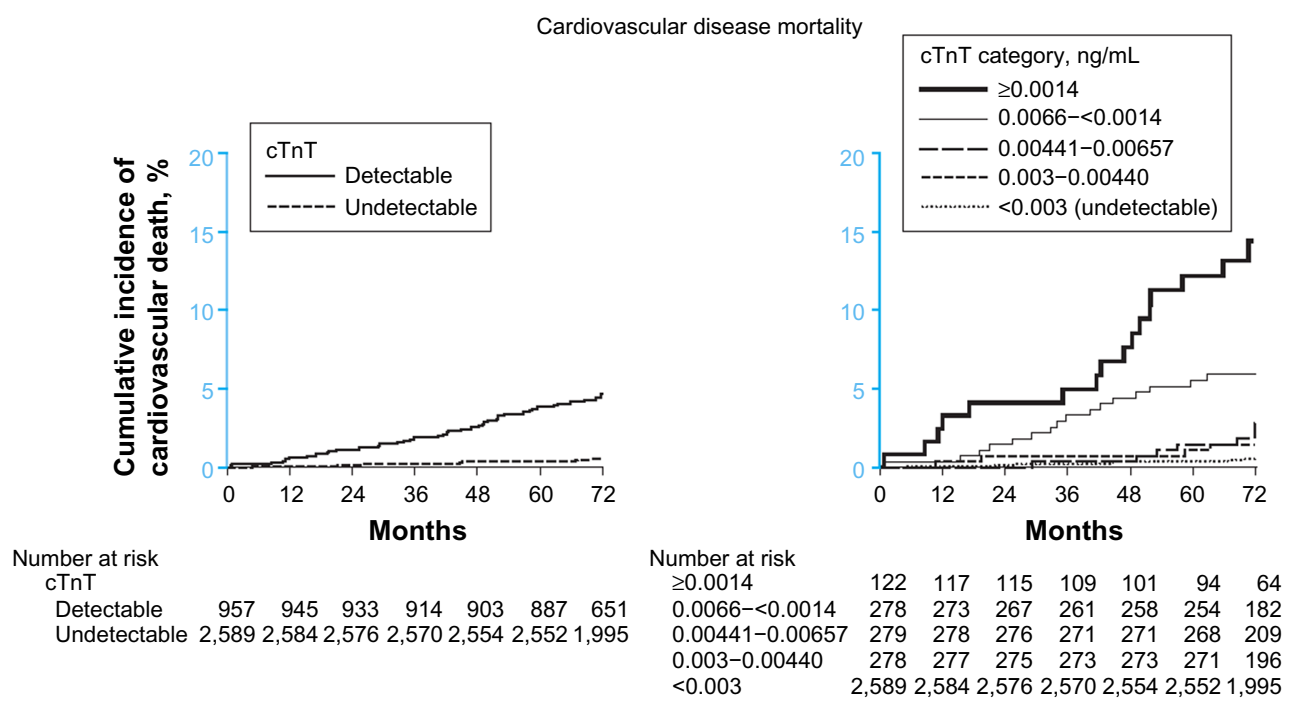

Figure 3 Cardiovascular disease mortality among a group of community-dwelling subjects enrolled in the Dallas Heart Study.

Notes: $P<0.00$ I for all between-group comparisons by the log-rank test. Reproduced from de Lemos JA, Drazner MH, Omland T, et al. Association of troponin T detected with a highly sensitive assay and cardiac structure and mortality risk in the general population. JAMA. 2010;304(22):2503-25I2.37 Copyright (C 20I0 American Medical Association. All rights reserved.

Abbreviation: $\mathrm{cTnT}$, cardiac troponin T.

\section{High sensitivity cTn assays and the elderly}

High sensitivity cTn assays will detect troponin in a substantial number of asymptomatic elderly persons. In the DHS, age was found to be an independent predictor of a measurable hs-cTnT among asymptomatic adults. ${ }^{37}$ In an Italian cohort of community dwelling subjects aged $65-84$ years, circulating levels of hs-cTnT were detected in $18 \%$ of the females and $41 \%$ of the males. Correlation with echocardiographic data indicated an association between left ventricular mass, mid-wall fractional shortening, and diastolic dysfunction. ${ }^{39}$ Eggers et al evaluated troponin in 940 elderly men, 379 of whom had an established diagnosis of coronary artery disease and 561 of whom did not. Using an hs-cTnT assay with a measureable range (3.0-10,000 ng/L), a detectable troponin level was found in $92.8 \%$ of the patients. ${ }^{40}$ In another study, among patients $>70$ years old, the same group noted that hs-cTnT levels increased gradually with time and were on average $45 \%$ higher in the same patient after five years. ${ }^{41}$

Elderly persons presenting to emergency departments are also commonly found to have measurable troponin levels using hs-cTn assays. Menacer et $\mathrm{al}^{42}$ evaluated troponin levels among 362 patients presenting to an emergency department without chest pain or signs of CVD. They used four hs-cTn assays including an hs-cTnT assay (lower limit of quantification $13 \mathrm{ng} / \mathrm{L}$ ) and three different hs-cTnI assays (lower limit of quantification 32, 40, and $30 \mathrm{ng} / \mathrm{L}$ ). As expected, the hs-cTnT proved the most sensitive assay, detecting a measurable troponin level in $81 \%$ of the patients.
The hs-cTnI assays proved less sensitive, detecting troponin in $15 \%-56 \%$ of this cohort. ${ }^{42}$ It will be impossible using high-sensitivity assays to assign a working diagnosis of AMI using only a serum troponin concentration, especially among elderly patients.

\section{Copeptin}

Arginine vasopressin is released from the neurohypophysis in response to changes in plasma osmolality and is involved in osmoregulation and cardiovascular homeostasis. Activation of the arginine vasopressin system is part of the endogenous response to stress, such as is encountered in the setting of AMI. Vasopressin degrades rapidly in circulation and has not been found to be useful as a biomarker. Instead, copeptin, the more stable $\mathrm{C}$-terminal fragment of provasopressin, has emerged as a promising surrogate for vasopressin in the characterization of the role of the arginine-vasopressin system in CVD. It has been hypothesized that the addition of copeptin levels to a diagnostic strategy for AMI might increase sensitivity and specificity. Reichlin et $\mathrm{al}^{43}$ used a conventional cTnT assay and a novel copeptin assay to risk stratify 492 patients presenting to an emergency department with symptoms suggestive of AMI. They found that copeptin levels were elevated very early in relation to the onset of symptoms and when compared with cTnT (Figure 4). Furthermore, when cTnT and copeptin measurements were evaluated in combination, improved diagnostic sensitivity for AMI was noted. This was true when the combination was compared to either assay alone, or the combination of 


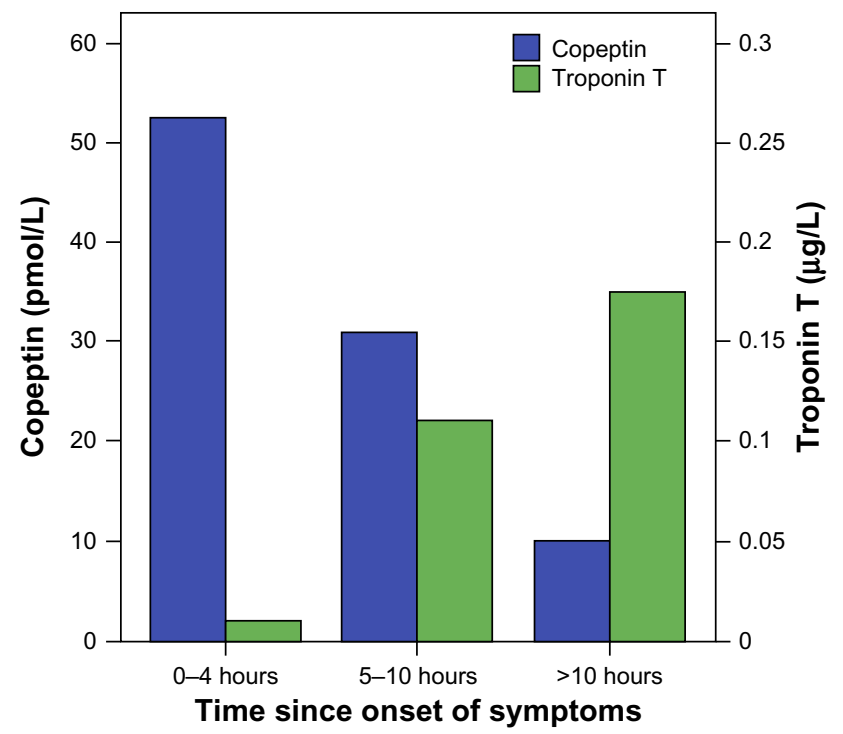

Figure 4 Copeptin (blue) and troponin T (green) levels at presentation in relation to the time since the onset of symptoms among patients found to have an acute myocardial infarction.

Note: Reprinted from J Am Coll Cardiol, 54(I), Reichlin T, Hochholzer W, Stelzig C, et al, Incremental value of copeptin for rapid rule out of acute myocardial infarction, pages 60-68. ${ }^{43}$ Copyright (C) 2009 with permission from Elsevier.

cTnT and CK-MB. Of equal importance, the combination of cTnT and copeptin was very effective in identifying patients without AMI (negative predictive value 99.7\%). ${ }^{43}$

\section{Growth-differentiation factor-I 5}

Growth-differentiation factor (GDF)-15 is a member of the transforming growth factor-B cytokine superfamily. While GDF-15 is weakly expressed in most tissues under physiological conditions, its expression levels increase in response to pathological stress associated with inflammation or tissue injury. CVD and AMI are known to be inflammatory states. ${ }^{44}$ GDF-15 concentrations are elevated in AMI and in chronic HF. In both cases, these elevations have been associated with a subsequent increase in mortality. ${ }^{45-48}$ Recently, GDF-15 was one of several biomarkers evaluated among a group of patients admitted with chest pain and an "undetectable" troponin. The study enrolled 1,247 patients, all of whom were admitted with concern for AMI, but who had undetectable serum cTnT levels measured by a conventional assay. The authors found that in this low risk cohort, a GDF-15 level of $>1800 \mathrm{ng} / \mathrm{L}$ was associated with an increased risk of death or myocardial infarction on follow-up. ${ }^{49}$

\section{Conclusion}

The practice of cardiovascular medicine has been forever changed by the ability to measure biomarkers.
Troponin measurements have become an integral part of contemporary diagnostic and patient management algorithms. The current generation of troponin assays has been shown to better identify patients with AMI who are at a high risk for adverse events. Additionally, patients with an elevated troponin seem to benefit from an aggressive therapeutic strategy. The prognostic power of other biomarkers such as NT-BNP has been established, but no link between these biomarkers and a therapeutic strategy has been established. Unfortunately, the studies upon which these conclusions were based enrolled relatively few elderly patients.

Research continues to find the next great biomarker for clinical practice and a few of the emerging candidates, as well as their potential utility, have been discussed in this paper. Elderly patients represent the largest portion of cardiovascular patients. There has been an increasing realization for the need to have algorithms that consider the patient's age and other comorbidities rather than a one-size-fits-all approach to abnormal levels of biomarkers. With the increasing number of available biomarkers, the practice of medicine will depend more heavily on developing appropriate testing for all patients.

\section{Disclosure}

None of the authors have any conflict of interest in relation to this paper.

\section{References}

1. US Census Bureau, P.D. Annual Estimates of the Resident Population for Selected Age Groups by Sex for the United States, States, Counties, and Puerto Rico Commonwealth and Municipios: April 1, 2010 to July 1, 2012 2013 [cited 2013 January 30, 2013]; Available from: http://factfinder2. census.gov/faces/tableservices/jsf/pages/productview.xhtml?src=bkmk. Accessed January 23, 2014.

2. Go AS, Mozaffarian D, Roger VL, et al; American Heart Association Statistics Committee and Stroke Statistics Subcommittee. Heart disease and stroke statistics - 2013 update: a report from the American Heart Association. Circulation. 2013;127(1):e6-e245.

3. Katus HA, Remppis A, Scheffold T, Diederich KW, Kuebler W. Intracellular compartmentation of cardiac troponin $\mathrm{T}$ and its release kinetics in patients with reperfused and nonreperfused myocardial infarction. Am J Cardiol. 1991;67(16):1360-1367.

4. Christ M, Bertsch T, Popp S, Bahrmann P, Heppner HJ, Müller C. Highsensitivity troponin assays in the evaluation of patients with acute chest pain in the emergency department. Clin Chem Lab Med. 2011;49(12): 1955-1963.

5. Hamm CW, Ravkilde J, Gerhardt W, et al. The prognostic value of serum troponin T in unstable angina. N Engl J Med. 1992;327(3): $146-150$.

6. Morrow DA, Antman EM, Tanasijevic M, et al. Cardiac troponin I for stratification of early outcomes and the efficacy of enoxaparin in unstable angina: a TIMI-11B substudy. J Am Coll Cardiol. 2000;36(6): $1812-1817$. 
7. Newby LK, Ohman EM, Christenson RH, et al. Benefit of glycoprotein IIb/IIIa inhibition in patients with acute coronary syndromes and troponin t-positive status: the paragon-B troponin $\mathrm{T}$ substudy. Circulation. 2001;103(24):2891-2896.

8. Morrow DA, Cannon CP, Rifai N, et al; TACTICS-TIMI 18 Investigators. Ability of minor elevations of troponins I and $\mathrm{T}$ to predict benefit from an early invasive strategy in patients with unstable angina and non-ST elevation myocardial infarction: results from a randomized trial. JAMA. 2001;286(19):2405-2412.

9. Yan AT, Yan RT, Tan M, et al; Canadian Acute Coronary Syndromes Registry Investigators. In-hospital revascularization and one-year outcome of acute coronary syndrome patients stratified by the GRACE risk score. Am J Cardiol. 2005;96(7):913-916.

10. Antman EM, Cohen M, Bernink PJ, et al. The TIMI risk score for unstable angina/non-ST elevation MI: A method for prognostication and therapeutic decision making. JAMA. 2000;284(7):835-842.

11. Thygesen K, Alpert JS, Jaffe AS, et al. Third universal definition of myocardial infarction. Circulation. 2012;126(16):2020-2035.

12. Storrow AB, Lardaro TA, Alexander PT, Apple FS. How low can we go? The high-sensitivity cardiac troponin debate. Ann Emerg Med. 2013;62(6):580-583.

13. Apple FS, Parvin CA, Buechler KF, Christenson RH, Wu AH, Jaffe AS. Validation of the 99th percentile cutoff independent of assay imprecision (CV) for cardiac troponin monitoring for ruling out myocardial infarction. Clin Chem. 2005;51(11):2198-2200.

14. Panteghini M, Gerhardt W, Apple FS, Dati F, Ravkilde J, Wu AH. Quality specifications for cardiac troponin assays. Clin Chem Lab Med. 2001;39(2):175-179.

15. Adams JE 3rd, Bodor GS, Dávila-Román VG, et al. Cardiac troponin I. A marker with high specificity for cardiac injury. Circulation. 1993;88(1):101-106.

16. Li D, Keffer J, Corry K, Vazquez M, Jialal I. Nonspecific elevation of troponin T levels in patients with chronic renal failure. Clin Biochem. 1995;28(4):474-477.

17. Missov E, Calzolari C, Pau B. Circulating cardiac troponin I in severe congestive heart failure. Circulation. 1997;96(9):2953-2958.

18. La Vecchia L, Mezzena G, Ometto R, et al. Detectable serum troponin I in patients with heart failure of nonmyocardial ischemic origin. Am J Cardiol. 1997;80(1):88-90.

19. Vasile VC, Chai HS, Abdeldayem D, Afessa B, Jaffe AS. Elevated cardiac troponin $\mathrm{T}$ levels in critically ill patients with sepsis. Am J Med. 2013;126(12):1114-1121.

20. Meyer T, Binder L, Hruska N, Luthe H, Buchwald AB. Cardiac troponin I elevation in acute pulmonary embolism is associated with right ventricular dysfunction. J Am Coll Cardiol. 2000;36(5): 1632-1636.

21. Bonnefoy E, Godon P, Kirkorian G, Chabaud S, Touboul P. Significance of serum troponin I elevation in patients with acute aortic dissection of the ascending aorta. Acta Cardiol. 2005;60(2):165-170.

22. Waxman DA, Hecht S, Schappert J, Husk G. A model for troponin I as a quantitative predictor of in-hospital mortality. $\mathrm{J} \mathrm{Am} \mathrm{Coll} \mathrm{Cardiol}$. 2006;48(9):1755-1762.

23. de Lemos JA. Increasingly sensitive assays for cardiac troponins: a review. JAMA. 2013;309(21):2262-2269.

24. de Lemos JA, Morrow DA, deFilippi CR. Highly sensitive troponin assays and the cardiology community: a love/hate relationship? Clin Chem. 2011;57(6):826-829.

25. Eggers KM, Lind L, Ahlström H, et al. Prevalence and pathophysiological mechanisms of elevated cardiac troponin I levels in a population-based sample of elderly subjects. Eur Heart J. 2008;29(18): 2252-2258.

26. Wallace TW, Abdullah SM, Drazner MH, et al. Prevalence and determinants of troponin T elevation in the general population. Circulation. 2006;113(16):1958-1965.

27. Maisel AS. The diagnosis of acute congestive heart failure: role of BNP measurements. Heart Fail Rev. 2003;8(4):327-334.
28. Tulevski II, ten Wolde M, van Veldhuisen DJ, et al. Combined utility of brain natriuretic peptide and cardiac troponin $\mathrm{T}$ may improve rapid triage and risk stratification in normotensive patients with pulmonary embolism. Int J Cardiol. 2007;116(2):161-166.

29. Charpentier J, Luyt CE, Fulla Y, et al. Brain natriuretic peptide: a marker of myocardial dysfunction and prognosis during severe sepsis. Crit Care Med. 2004;32(3):660-665.

30. James SK, Lindahl B, Siegbahn A, et al. N-terminal pro-brain natriuretic peptide and other risk markers for the separate prediction of mortality and subsequent myocardial infarction in patients with unstable coronary artery disease: a Global Utilization of Strategies To Open occluded arteries (GUSTO)-IV substudy. Circulation. 2003;108(3):275-281.

31. Raymond I, Groenning BA, Hildebrandt PR, et al. The influence of age, sex and other variables on the plasma level of $\mathrm{N}$-terminal pro brain natriuretic peptide in a large sample of the general population. Heart. 2003;89(7):745-751.

32. Redfield MM, Rodeheffer RJ, Jacobsen SJ, Mahoney DW, Bailey KR, Burnett JC Jr. Plasma brain natriuretic peptide concentration: impact of age and gender. J Am Coll Cardiol. 2002;40(5):976-982.

33. Heeschen C, Hamm CW, Bruemmer J, Simoons ML. Predictive value of $\mathrm{C}$-reactive protein and troponin $\mathrm{T}$ in patients with unstable angina: a comparative analysis. CAPTURE Investigators. Chimeric c7E3 AntiPlatelet Therapy in Unstable angina REfractory to standard treatment trial. J Am Coll Cardiol. 2000;35(6):1535-1542.

34. Liuzzo G, Biasucci LM, Gallimore JR, et al. The prognostic value of C-reactive protein and serum amyloid a protein in severe unstable angina. $N$ Engl J Med. 1994;331(7):417-424.

35. Sabatine MS, Morrow DA, de Lemos JA, et al. Multimarker approach to risk stratification in non-ST elevation acute coronary syndromes: simultaneous assessment of troponin I, C-reactive protein, and B-type natriuretic peptide. Circulation. 2002;105(15):1760-1763.

36. McCann CJ, Glover BM, Menown IB, et al. Prognostic value of a multimarker approach for patients presenting to hospital with acute chest pain. Am J Cardiol. 2009;103(1):22-28.

37. de Lemos JA, Drazner MH, Omland T, et al. Association of troponin T detected with a highly sensitive assay and cardiac structure and mortality risk in the general population. JAMA. 2010;304(22):2503-2512.

38. Reichlin T, Hochholzer W, Bassetti S, et al. Early diagnosis of myocardial infarction with sensitive cardiac troponin assays. $N$ Engl $J$ Med. 2009;361(9):858-867.

39. Masson S, Latini R, Mureddu GF, et al; PREDICTOR study. High-sensitivity cardiac troponin $\mathrm{T}$ for detection of subtle abnormalities of cardiac phenotype in a general population of elderly individuals. J Intern Med. 2013;273(3):306-317.

40. Eggers KM, Al-Shakarchi J, Berglund L, et al. High-sensitive cardiac troponin $\mathrm{T}$ and its relations to cardiovascular risk factors, morbidity, and mortality in elderly men. Am Heart J. 2013;166(3):541-548.

41. Eggers KM, Venge P, Lindahl B, Lind L. Cardiac troponin I levels measured with a high-sensitive assay increase over time and are strong predictors of mortality in an elderly population. J Am Coll Cardiol. 2013;61(18):1906-1913.

42. Menacer S, Claessens YE, Meune C, et al. Reference range values of troponin measured by sensitive assays in elderly patients without any cardiac signs/symptoms. Clin Chim Acta. 2013;417:45-47.

43. Reichlin T, Hochholzer W, Stelzig C, et al. Incremental value of copeptin for rapid rule out of acute myocardial infarction. $J \mathrm{Am}$ Coll Cardiol. 2009;54(1):60-68.

44. Alexander RW. Inflammation and coronary artery disease. $N$ Engl J Med. 1994;331(7):468-469.

45. Bonaca MP, Morrow DA, Braunwald E, et al. Growth differentiation factor-15 and risk of recurrent events in patients stabilized after acute coronary syndrome: observations from PROVE IT-TIMI 22. Arterioscler Thromb Vasc Biol. 2011;31(1):203-210.

46. Kempf T, Eden M, Strelau J, et al. The transforming growth factor-beta superfamily member growth-differentiation factor- 15 protects the heart from ischemia/reperfusion injury. Circ Res. 2006;98(3):351-360. 
47. Wollert KC, Kempf T, Peter T, et al. Prognostic value of growthdifferentiation factor-15 in patients with non-ST-elevation acute coronary syndrome. Circulation. 2007;115(8):962-971.

48. Kempf T, von Haehling S, Peter T, et al. Prognostic utility of growth differentiation factor-15 in patients with chronic heart failure. $J \mathrm{Am}$ Coll Cardiol. 2007;50(11):1054-1060.

49. Meune C, Balmelli C, Twerenbold R, et al. Utility of 14 novel biomarkers in patients with acute chest pain and undetectable levels of conventional cardiac troponin. Int J Cardiol. 2013;167(4):1164-1169.
50. Archan S, Fleisher LA. From creatine kinase-MB to troponin: the adoption of a new standard. Anesthesiology. 2010;112(4):1005-1012.

51. Mohammed AA, Januzzi JL Jr. Clinical applications of highly sensitive troponin assays. Cardiol Rev. 2010;18(1):12-19.

52. Korley FK, Jaffe AS. Preparing the United States for high-sensitivity cardiac troponin assays. J Am Coll Cardiol. 2013;61(17):1753-1758.

\section{Publish your work in this journal}

Clinical Interventions in Aging is an international, peer-reviewed journal focusing on evidence-based reports on the value or lack thereof of treatments intended to prevent or delay the onset of maladaptive correlates of aging in human beings. This journal is indexed on PubMed Central, MedLine, the American Chemical Society's 'Chemical Abstracts
Service' (CAS), Scopus and the Elsevier Bibliographic databases. The manuscript management system is completely online and includes a very quick and fair peer-review system, which is all easy to use. Visit http://www.dovepress.com/testimonials.php to read real quotes from published authors.

Submit your manuscript here: http://www.dovepress.com/clinical-interventions-in-aging-journal 